\title{
Sex-related interactive effect of smoking and household pets on asthma incidence
}

\author{
Y. Chen*, R. Dales*,\#, M. Tang*, D. Krewski*,\#
}

Sex-related interactive effect of smoking and household pets on asthma incidence. Y. Chen, R. Dales, M. Tang, D. Krewski. C ERS Journals Ltd 2002.

ABSTRACT: The authors examined the interactive effect of smoking and pets at home on the incidence of asthma and the difference between sexes.

The longitudinal data from the first two cycles of the National Population Health Survey, conducted in Canada, were used. A total of 12,636 subjects who reported no asthma at baseline were included in the analysis.

The 2-yr cumulative incidence of asthma was higher in females than in males. Female sex and household pets demonstrated a significant interaction in the development of asthma. After adjustment for age, immigration and history of allergy, the odds ratio for smoking in relation to the asthma incidence was $2.50(95 \%$ confidence interval: 1.24-5.05) for females who had pets at home and close to unity for those who had no pets. The incidence of asthma was not associated with smoking status and household pets in males.

These results indicate that smoking, having pets at home and other environmental factors can partly explain asthma morbidity among female Canadians.

Eur Respir J 2002; 20: 1162-1166.
* Dept of Epidemiology and Community Medicine and ${ }^{\#}$ Dept of Medicine, Faculty of Medicine, University of Ottawa, Ottawa, Ontario, Canada.

Correspondence: Y. Chen, Dept of Epidemiology and Community Medicine, Faculty of Medicine, University of Ottawa, 451 Smyth Road, Ottawa, Ontario, Canada, K1H 8M5.

Fax: 16135625465

E-mail: ychen@uottawa.ca

Keywords: Asthma, interaction, longitudinal study, pets, sex, smoking

Received: August 162001

Accepted after revision: April 272002

This study was supported by a National Health Research and Development Programme grant (6606-06-1998/ 2640023). Y. Chen currently holds a Canadian Institutes of Health Research Investigator Award. D. Krewski is the NSERC/SSHRC/McLaughlin Chair in Population Health Risk Assessment at the University of Ottawa.
Previous studies have documented that females have an increased incidence of asthma as compared to males [1-3], although the opposite is true for young children [4-7]. Similarly, the rate of asthma admission is lower for pre-pubertal females than males, but higher for adult females than males [8]. The reasons for these sex differences in asthma morbidity remain to be explored.

Cigarette smoking is the most important risk factor for the development of chronic bronchitis and emphysema. However, the relationship between smoking and asthma remains unclear [9]. The current authors' most recent analysis of cross-sectional data from the National Population Health Survey (NPHS) conducted in 1994-1995 demonstrated that smoking was associated with increased prevalence of asthma in females, but not in males [10]. Another recent study in Sweden also found that smoking was associated with an increased incidence of asthma in females only [8].

The objective of the present study was to examine sex-related differences in susceptibility to environmental exposures, utilising longitudinal data from the Canadian National Population Health Survey. The authors hypothesised that females may be more susceptible to the deleterious effects of cigarette smoke and exposure to aeroallergens.

\section{Materials and methods}

The present analysis was based on longitudinal data from first and second cycles of the NPHS conducted by Statistics Canada in 1994-1995 and 1996-1997, respectively. These two NPHS cycles provided information on a panel of individuals followed over a 2-yr period. The design and execution of the baseline survey have been detailed elsewhere [11-14]. In brief, the target population included household residents in all 10 provinces, excluding Indian reserves, Canadian forces bases and some remote areas in Quebec and Ontario. The NPHS used a two-stage stratified sampling design to draw a representative sample of $\sim 19,600$ households with a national response rate of $88 \%$. Some information was collected from all household members, with one person in each household randomly selected for a more in-depth interview [11].

The longitudinal panel comprised every selected household member who had completed at least the 
general questionnaire in the first cycle [12]. Of the 17,626 subjects of $\geqslant 12$ yrs of age who participated in the NPHS 1994-1995, 14,786 were eligible for the longitudinal panel. Ineligible subjects were those sponsored by provincial governments to enlarge the sample size in their respective provinces. In the present analysis, subjects who had reported having asthma in the first cycle and who did not respond to questions about asthma in either the first or second cycle were excluded. This left 12,636 subjects $(5,747$ males and 6,889 females) who participated in both cycles for analysis.

Respondents who answered the following question affirmatively were considered as having asthma: "Do you have asthma diagnosed by a health professional?" Incident asthma cases were those who reported no asthma in the first cycle, but reported having asthma in the second cycle.

Current smokers were defined as respondents who reported smoking cigarettes every day at the time of the survey. Exsmokers were those who reported smoking cigarettes daily in the past, but who were not smoking at the time of survey. Otherwise, subjects were classified as nonsmokers. Smoking status did not change dramatically during the 2-yr study period, with the great majority of the subjects $(87.6 \%$ of males and $88.4 \%$ of females) classified in the same smoking status category in both cycles. The present analysis was based on smoking status defined at baseline (NPHS 1994-1995). A positive history of allergy was indicated if an affirmative response was given to either of the following questions: "Do you have any food allergies diagnosed by a health professional?" or "Do you have other allergies diagnosed by a health professional?" Other variables included in the analysis were age $(12-24,25-39,40-54,55-69$ or $\geqslant 70 \mathrm{yrs})$, immigrant status (yes or no), household size (one, two, three or four or more people), number of bedrooms (less than three or three or more), any pets at home (yes or no), regular drinking (yes or no), regular exercise (yes or no), body mass index (BMI: $<20.0$, $20.0-24.9,25.0-27.9$ or $\geqslant 28.0 \mathrm{~kg} \cdot \mathrm{m}^{-2}$ ), education level (low or high) and income adequacy (low, middle or high).

The 2-yr cumulative incidence of asthma and corresponding 95\% confidence intervals (CIs) were calculated according to various risk factors. Logistic regression models were used for multivariate analysis.

The NPHS employed a complex survey design. The design effect (DEF) [15] was taken into consideration by using the Rao-Wu bootstrap method [16, 17], which has been described in detail in a previous analysis [14]. Statistical Analysis System (SAS) macros for the bootstrap approach were developed by Statistics Canada, and the statistical analyses were conducted using SAS 6.12 [18].

\section{Results}

Table 1 shows that the 2-yr cumulative incidence of asthma in females was higher than that in males in younger age groups. Male and female subjects $\geqslant 55 \mathrm{yrs}$ of age exhibited similar incidences of

Table 1. - Two-year cumulative incidence of asthma according to various risk factors: longitudinal observations from the National Population Health Surveys 1994-1996

\begin{tabular}{|c|c|c|c|c|c|c|}
\hline \multirow[t]{2}{*}{ Risk Factor } & \multicolumn{3}{|c|}{ Males } & \multicolumn{3}{|c|}{ Females } \\
\hline & Subjects $n$ & $\%$ & $95 \% \mathrm{CI}^{\#}$ & Subjects $\mathrm{n}$ & $\%$ & $95 \% \mathrm{CI}$ \\
\hline \multicolumn{7}{|l|}{ Age yrs } \\
\hline $12-24$ & 1094 & 2.8 & $1.7-3.9$ & 1134 & 5.3 & $3.6-7.0$ \\
\hline $25-39$ & 1740 & 1.2 & $0.6-1.7$ & 2074 & 2.6 & $1.8-3.5$ \\
\hline $44-54$ & 1443 & 1.2 & $0.4-2.0$ & 1498 & 2.4 & $1.5-3.3$ \\
\hline $55-69$ & 925 & 1.4 & $0.5-2.4$ & 1197 & 1.6 & $0.8-2.4$ \\
\hline$\geqslant 70$ & 545 & 2.2 & $0.9-3.6$ & 986 & 2.6 & $1.3-3.8$ \\
\hline \multicolumn{7}{|l|}{ Pets } \\
\hline Yes & 2592 & 1.6 & $1.0-2.2$ & 3107 & 3.7 & $2.9-4.6$ \\
\hline No & 3154 & 1.7 & $1.1-2.2$ & 3780 & 2.3 & $1.7-2.9$ \\
\hline Unknown & 1 & & & 2 & & \\
\hline \multicolumn{7}{|l|}{ Any allergy } \\
\hline Yes & 835 & 3.8 & $2.3-5.3$ & 1449 & 6.2 & $4.6-7.9$ \\
\hline No & 4912 & 1.2 & $0.8-1.6$ & 5440 & 2.1 & $1.6-2.6$ \\
\hline \multicolumn{7}{|l|}{ Immigrant } \\
\hline Yes & 761 & 1.2 & $0.4-1.9$ & 930 & 1.4 & $0.4-2.5$ \\
\hline No & 4981 & 1.8 & $1.3-2.2$ & 5957 & 3.3 & $2.8-3.9$ \\
\hline Unknown & 5 & & & 2 & & \\
\hline \multicolumn{7}{|l|}{ Smoking status } \\
\hline Nonsmoker & 2435 & 1.7 & $1.1-2.3$ & 3723 & 2.4 & $1.8-3.0$ \\
\hline Exsmoker & 1699 & 1.3 & $0.6-1.9$ & 1532 & 3.2 & $1.9-4.4$ \\
\hline Smoker & 1612 & 2.0 & $1.1-2.9$ & 1630 & 4.2 & $3.0-5.4$ \\
\hline Unknown & 1 & & & 4 & & \\
\hline
\end{tabular}

There was no discernible association between asthma incidence and the following variables: household size, number of bedrooms, educational level, income adequacy, alcohol use or regular exercise. Data available upon request. CI: confidence interval. \#: $95 \%$ bootstrap CI. 
asthma. Females who had any pets at home or who were nonimmigrants were more likely to develop asthma than females who had no pets at home or who were immigrants. These associations were less pronounced in male subjects.

Female but not male smokers had a higher incidence of asthma compared with nonsmokers during the 2-yr study period. The incidence of asthma was approximately three-fold higher for those who had a history of allergy.
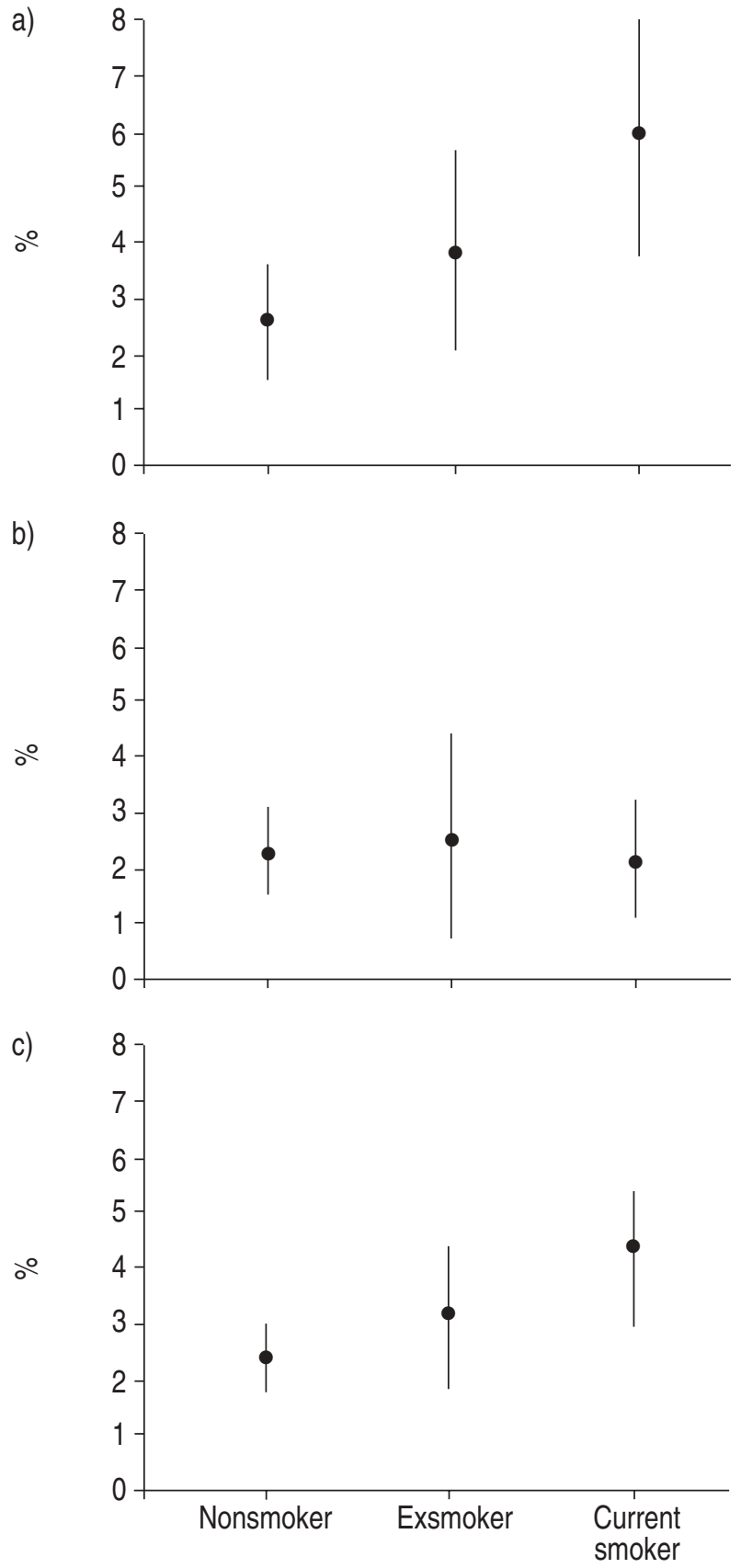

Fig. 1.- Unadjusted 2-yr cumulative incidence and 95\% confidence intervals for asthma by smoking status and having pets at home in females: longitudinal observations from the National Population Health Surveys 1994-1996. a) With pets, b) without pets and c) all subjects.
The presence of household pets notably modified the influence of smoking on asthma incidence in females. A significant effect of smoking on asthma incidence was observed among females who had pets at home, while the incidence of asthma showed little variation among female smokers, exsmokers and nonsmokers who did not have pets at home (fig. 1). The relationship between smoking and asthma incidence in females did not appear to be appreciably affected by household size, number of bedrooms, history of allergy, educational level, income adequacy, regular drinking, regular exercise or BMI at baseline. No significant effect of smoking on the incidence of asthma in males was found in these subgroups.

The interactive effect of smoking and household pets on a multiplicative scale was further examined using a multiple logistic regression model including age, immigrant status and history of allergy (table 2). Using nonsmoking females as a reference point, the adjusted odds ratio for smoking in relation to the asthma incidence was 2.50 (95\% CI: 1.24-5.05) for females who had pets at home and $0.95(95 \% \mathrm{CI}$ : $0.49-1.85$ ) for those who did not have pets at home. The interaction between exsmoking and any pets at home was not statistically significant $(\mathrm{p}>0.10)$. The odds ratio for asthma was 1.49 (95\% CI: 0.87-2.56) among female exsmokers compared with nonsmokers. The relationship between smoking, having pets at home and asthma incidence was similar when income adequacy and/or BMI at baseline were included in the model.

\section{Discussion}

The present analysis has demonstrated an association between smoking and asthma in females, but not in males. The results are consistent with the current authors' previous findings based on cross-sectional data from the NPHS [10]. A recent study from Sweden, based on data from a random sample of 15,813 persons, found that females had a significantly higher incidence of adult-onset asthma than males [8]. Compared with nonsmokers, the incidence rate ratio for female smokers was 1.6 (95\% CI: 1.1-2.2), while the incidence rate ratio for male smokers was close to unity.

Some discrepancies exist among studies with regard to the relationship between smoking and asthma. Because asthmatics are less likely not to start smoking and more likely to quit smoking if they do smoke, both smoking and asthma can be "causes" and "outcomes". While it is difficult to address this issue in cross-sectional studies, longitudinal studies do not completely overcome this limitation. Some researchers have speculated that individuals with sensitive airways are less likely to become regular smokers, and smokers who develop respiratory symptoms of any aetiology tend to quit smoking [19]. Smoking may also exacerbate asthma symptoms in susceptible individuals. Active smoking increased respiratory symptoms among those with asthma in one study [20] and was an independent risk factor for future asthma symptoms during adolescence in another study [21]. 
Table 2. - Multiple logistic regression coefficients for 2-yr cumulative incidence of asthma in relation to selected risk factors, the National Population Health Surveys 1994-1996

\begin{tabular}{|c|c|c|c|c|c|c|}
\hline \multirow[t]{2}{*}{ Risk factor } & \multicolumn{3}{|c|}{ Males } & \multicolumn{3}{|c|}{ Females } \\
\hline & $\beta^{\#}$ & $\mathrm{SE}^{\bullet}$ & $\mathrm{p}$-value & $\beta$ & SE & $\mathrm{p}$-value \\
\hline \multicolumn{7}{|l|}{ Age yrs } \\
\hline $12-24$ & & Ref. & & & Ref. & \\
\hline $25-39$ & -0.92 & 0.35 & 0.01 & -0.82 & 0.24 & $<0.01$ \\
\hline $44-54$ & -0.74 & 0.46 & 0.10 & -0.85 & 0.27 & $<0.01$ \\
\hline $55-69$ & -0.52 & 0.47 & 0.27 & -1.13 & 0.33 & $<0.01$ \\
\hline$\geqslant 70$ & 0.03 & 0.46 & 0.95 & -0.57 & 0.35 & 0.10 \\
\hline \multicolumn{7}{|l|}{ Immigrant } \\
\hline Yes & -0.31 & 0.41 & 0.46 & 0.58 & 0.48 & 0.22 \\
\hline No & & Ref. & & & Ref. & \\
\hline \multicolumn{7}{|l|}{ Pets } \\
\hline Yes & -0.15 & 0.35 & 0.67 & 0.02 & 0.24 & 0.92 \\
\hline No & & Ref. & & & Ref. & \\
\hline \multicolumn{7}{|l|}{ Any allergy } \\
\hline Yes & 1.17 & 0.29 & $<0.01$ & 1.07 & 0.20 & $<0.01$ \\
\hline No & & Ref. & & & Ref. & \\
\hline \multicolumn{7}{|l|}{ Smoking status } \\
\hline Nonsmoker & & Ref. & & & Ref. & \\
\hline Exsmoker & -0.03 & 0.39 & 0.94 & 0.40 & 0.28 & 0.15 \\
\hline Smoker & 0.47 & 0.42 & 0.27 & -0.05 & 0.34 & 0.89 \\
\hline Pets and smoking & 0.03 & $0.63\left(0.04^{+}\right)$ & 0.96 & 0.96 & $0.43\left(0.03^{+}\right)$ & 0.02 \\
\hline
\end{tabular}

Ref.: reference. ${ }^{\#}$ : logistic regression coefficient; ${ }^{\circ}$ : bootstrap SE; ${ }^{+}$: covariance of smoking and having any pets at home.

Results for the relationship between household pets and asthma are also inconsistent. The relative risk in a random sample of 859 adult Swedes was 3.6 for asthma in relation to pets, higher than that for grass and dust mites [22]. Among asthmatic children in Singapore, those with pets at home were more symptomatic than those without pets at home with a relative risk of 1.3 [23]. However, Siracusa et al. [24] did not find household pets to be a risk factor for asthma or rhinitis in a random sample of Italians of $\leqslant 69$ yrs of age. This prevalence study also showed that cigarette smoking was inversely associated with asthma, suggesting that asthma may have influenced household exposures rather than the other way around [24].

Allergic sensitisation, as judged by the skin-prick test and specific immunoglobulin (Ig)E antibodies, is associated with asthma [8,25]. A further question is to what degree allergic sensitisation translates into clinical effects from exposure to the allergen in question. A Danish cross-sectional study of 120 adult asthmatics sensitised to cats and dogs found that patients with a pet at home had more symptoms, required more corticosteroid, and had higher eosinophilic counts as compared to those without pets [26].

The present analysis also indicates that females are more susceptible to asthma than males as a consequence of having household pets. SUNYER et al. [27] found that skin-test reactivity to Alternaria and IgE specific to cat and grass allergens, was associated with a decrease in forced expiratory volume in one second in females but not males, after adjusting for bronchial hyperreactivity and cigarette smoking.

A positive interaction between smoking and pets at home in relation to the incidence of asthma in females, was observed. Female smokers who had household pets were more likely to develop asthma during the 2-yr study period. There have been sporadic reports of interactive effects of inhalant exposures causing or exacerbating airways disease. Chronic exposure to grain dust and cigarette smoking are both associated with chronic airways disease. CHEN et al. [28] reported an interactive effect between grain farming exposure and smoking on lung function and chronic bronchitis in females but not males. Heavy cigarette smokers have been reported to have a higher rate of emergency department visits for respiratory disease following days of high ozone levels compared with nonsmokers [29]. More recently, Sunyer et al. [27] found that smoking modified the association between lung function and allergen sensitisation.

The reason that female smokers appear to be more susceptible to the influence of pets on developing asthma requires further exploration. Allergic individuals are more likely to have sensitive airways and are therefore less likely to become or continue to be regular smokers. Consequently, the combined effect of smoking and pet exposure is more likely to be underestimated rather than overestimated. In addition, no evidence of interaction between allergic status and smoking on the incidence of asthma was found. Both smoking and home pets involve a large number of constituents and the mechanisms underlying the interactive effect between these two variables can be complex.

The incidence of asthma in the present study was higher compared to, for example, the 1\% annual incidence rate of asthma in young Swedish adults [1]. The reported incidence of asthma depends on the true incidence in the population and on the operational definition of asthma used in a particular study. As there is no universally accepted definition of asthma, there is no universal benchmark for asthma incidence [30]. The purpose of this study was to determine 
whether the incidence of asthma was relatively higher in one subgroup than another.

In conclusion, the results of this study indicate that the incidence of asthma among Canadian female adolescents and adults is higher than among their male counterparts, with the sex difference much more pronounced for young and middle-aged individuals. Interactive effects of sex, cigarette smoking and pets can lead to a marked increase in the risk of developing asthma. Public and healthcare professionals need to be aware of the potentially large impact of these combined exposures on the incidence of asthma. The increased risk due to smoking, having pets at home and other environmental factors partly explain asthma morbidity among females.

\section{References}

1. Larsson L. Incidence of asthma in Swedish teenagers: relation to sex and smoking habits. Thorax 1995; 50: 260-264.

2. McWhorter WP, Polis MA, Kaslow RA. Occurrrence, predictors, and consequences of adult asthma in NHANES I and follow-up survey. Am Rev Respir Dis 1989; 139: 721-724.

3. Skobeloff EM, Spivey WH, St Clair SS, Scoffstall JM. The influence of age and sex on asthma admissions. J Am Med Assoc 1992; 268: 3437-3440.

4. Nolan T. Asthma. In: Pless IB, ed. The Epidemiology of Childhood Disorders. New York, Oxford University Press, 1994; pp. 430.

5. Dodge RR, Burrows B. The prevalence and incidence of asthma and asthma-like symptoms in a general population sample. Am Rev Respir Dis 1980; 122: 567-575.

6. Anderson HR, Pottier AC, Strachan DP. Asthma from birth to age 29: incidence and relation to prior an concurrent atopic disease. Thorax 1992; 47: 537-542.

7. Leynaert B, Bousquet J, Heary C, Liard R, Neukirch $\mathrm{F}$. Is bronchial hyperresponsiveness more frequent in women than in men?: a population-based study. Am J Respir Crit Care Med 1997; 156: 1413-1420.

8. Toren K, Hermansson BA. Incidence rate of adultonset asthma in relation to age, sex, atopy and smoking: a Swedish population-based study of 15813 adults. Int J Tuberc Lung Dis 1999; 3: 192-197.

9. Jarvis D, Burney P. The epidemiology of allergic disease. BMJ 1998; 316: 607-610.

10. Chen Y, Dales R, Krewski D, Breithaupt K. Increased effects of smoking and obesity on asthma among female Canadians: The National Population Health Survey (NPHS) 1994-1995. Am J Epidemiol 1999; 150: 255-262.

11. Statistics Canada. National Population Health Survey 1994-1995. Public Use Microdata Files. Ottawa, Ontario, Canada, Health Statistics Division, 1995.

12. Fobes P, Geran L. Cycle 2 and beyond: Preparing and storing longitudinal data of the National Population Health Survey. Proceedings of Statistics Canada Symposium 98. Longitudinal Analysis for Complex Surveys. Ottawa, Statistics Canada, 1998.

13. Peaudet MP, Chen J, Pérez C, Ross N, Wikins K. National Population Health Survey Overview 1996/1997. Ottawa, Ontario, Canada, Health Statistics Division, Statistics Canada. Catalogue 82-567, 1998; pp. $1-14$.

14. Chen Y, Dales R, Tang M, Krewski D. Obesity may increase the incidence of asthma in women but not in men: Longitudinal observations from the Canadian National Population Health Surveys. Am J Epidemiol 2002; 155: 191-197.

15. Skinner CJ, Holt D, Smith TMF, eds. Analysis of complex surveys. New York, John Wiley \& Sons Ltd, 1989.

16. Rao JNK, Wu CFJ. Resampling inference with complex survey data. J Am Stat Assoc 1998; 83: 231-241.

17. Rao JNK, Wu CFJ, Yue K. Some recent work on resampling methods for complex surveys. Survey Methodology 1992; 18: 209-217.

18. SAS Institute, Inc. SAS procedures guide. Release 6.12 edition. Cary, NC, SAS Institute, Inc., 1996.

19. Troisi RJ, Speizer FE, Rosner B, Trichopoulos D, Willett WC. Cigarette smoking and incidence of chronic bronchitis and asthma in women. Chest 1995; 108: 1557-1561.

20. Siroux V, Pin I, Oryszczyn MP, Le Moual N, Kauffmann F. Relationships of active smoking to asthma and asthma severity in the EGEA study. Epidemiological study on the Genetics and Environment of Asthma. Eur Respir J 2000; 15: 470-477.

21. Rasmussen F, Siersted HC, Lambrechtsen J, Hansen HS, Hansen NC. Impact of airway lability, atopy, and tobacco smoking on the development of asthma-like symptoms in asymptomatic teenagers. Chest 2000; 117: $1330-1335$.

22. Plaschke $\mathrm{P}$, Janson C, Norrman E, Bjornsson E, Ellbjar SW, Jarvholm B. Association between atopic sensitisation and asthma and bronchial hyperresponsiveness in Swedish adults: pets, and not mites, are the most important allergens. J Aller Clin Immuno 1999; 104: 58-65.

23. Chew FT, Teo J, Quak SH, Connett GJ, Lee BW. Presence of domestic pets and respiratory symptoms in asthmatic children. Ann Acad Med (Singapore) 1997; 26: 294-298.

24. Siracusa A, Marabini A, Sensi L, et al. Prevalence of asthma and rhinitis in Perugia, Italy. Monaldi Arch Chest Dis 1997; 52: 434 439.

25. Soriano JB, Anto JM, Sunyer J, et al. Risk of asthma in the general Spanish population attributable to specific immunoresponse. Spanish Group of the European Community Respiratory Health Survey. Int J Epidemiol 1999; 28: 728-734.

26. Plaschke P, Janson C, Balder B, Lowhagen O, Jarvholm B. Adult asthmatics sensitised to cats and dogs: symptoms, severity, and bronchial hyperresponsiveness in patients with furred animals at home and patients without these animals. Allergy 1999; 54: 843-850.

27. Sunyer J, Soriano J, Anto JM, et al. Sensitization to individual allergens as risk factors for lower FEV1 in young adults. European Community Respiratory Health Survey. Int J Epidemiol 2000; 29: 125-130.

28. Chen Y, Horne SL, McDuffie HH, et al. Combined effect of grain farming and smoking on lung function and the prevalence of chronic bronchitis. Int $J$ Epidemiol 1991; 20: 416-423.

29. Cassino C, Ito K, Bader I, Ciotoli C, Thurston G, Reibman J. Cigarette smoking and ozone-associated emergency department use for asthma by adults in New York City. Am J Respir Crit Care Med 1999; 159: 1773-1779.

30. Chen Y, Dales R, Tang M, Krewski D. Respond to "Overweight and Asthma". Am J Epidemiol 2002; 155: 201-202. 